\title{
POTASSIUM MODULATION OF METHIONINE UPTAKE IN ASTROCYTES IN VITRO
}

\author{
C. J. Cummins ${ }^{1,4}$, R. A. Glover ${ }^{2}$, And O. Z. Sellinger ${ }^{3}$ \\ ${ }^{1}$ Surgical Neurology Branch \\ National Institute of Neurological and Communicative \\ Disorders and Stroke \\ National Institutes of Health \\ Bethesda, Maryland 20205 \\ ${ }^{2}$ Department of Anatomy
}

The University of Michigan School of Medicine

Ann Arbor, Michigan 48109

${ }^{3}$ Mental Health Research Institute

The University of Michigan School of Medicine

Ann Arbor, Michigan 48109

Accepted January 13, 1982

\begin{abstract}
Methionine participates in a large variety of metabolic pathways in brain, and its transport may play an important regulatory role. The properties of methionine uptake were examined in a preparation of neonatal rat brain astrocytes. Uptake is linear for 15 minutes, up to $2.5 \mu \mathrm{M}$. At steady state conditions, methionine is concentrated 30-50-fold. Measured methionine homoexchange accounts for a significant fraction of uptake at concentrations greater than $10 \mu \mathrm{M}$. We recently reported that methionine uptake is decreased by elevations in extracellular $\mathrm{K}^{+}$. Potassium induced efflux cannot account for this apparent effect; and thus for concentrations less than $2.5 \mu \mathrm{M}$, and for short times of incubation, measured rates of methionine uptake represent unidirectional flux. At extracellular concentrations of $\mathrm{K}^{+}$equal to $6.9 \mathrm{mM}$, the apparent $V_{\max }$ of methionine transport is 182 $\mathrm{pmol} / \mathrm{min} / \mathrm{mg}$ protein, and the $K_{m}$ is $1.3 \mu \mathrm{M}$. Where $\mathrm{K}^{+}$is shifted to $11.9 \mathrm{mM}$, the $K_{m}$ remains unchanged, and the $V_{\max }$ is reduced by half.
\end{abstract}

\section{INTRODUCTION}

Methionine (MET) is a precursor of proteins, other amino acids, polyamines, and the multifunctional methyl donor S-adenosyl methionine. MET

${ }^{4}$ To whom all correspondence may be sent: 10A/3E68, SNB, NINCDS, NIH, Bethesda, MD, 20205, (301) 496-5728; 496-6628. 
may be transported from blood to brain where the MET concentration approaches $20-40 \mu \mathrm{M}(10)$. Thus transport may play a key role as the rate-limiting or regulatory step in many of the important pathways in which MET participates.

Brain appears similar to other tissues in many aspects of its amino acid transport (13). Amino acids are accumulated against a concentration gradient, and transport systems discriminate between classes of amino acids based on structural features. Sershen and Lajtha (13) have recently shown that MET appears to be transported primarily by the L (or leucine) preferring system in brain, but MET also antagonizes transport of the A (or alanine) preferring system, suggesting that MET may be transported by the A system as well.

Despite an intense interest, most aspects of neuronal-glial interaction remain obscure. One potential mechanism by which neuronal metabolic status may be communicated to glia is by elevations in extracellular $\mathrm{K}^{+}$. Elevated extracellular $\mathrm{K}^{+}$has been shown to affect glial oxygen uptake (7), glucose uptake $(4,6)$ and oxidation state (14). Schousboe et al. (12) demonstrated that GABA uptake was modulated by elevations in extracellular $\mathrm{K}^{+}$, and we demonstrated that elevations in extracellular $\mathrm{K}^{+}$ modulated the uptake of methionine into primary cultures of rat brain astrocytes (6). We did not rule out possible confounding effects such as a potassium-induced efflux or homoexchange. We present here evidence to support a direct effect of extracellular $\mathrm{K}^{+}$on the kinetic properties of the transport system for methionine in primary cultures of rat brain astrocytes.

\section{EXPERIMENTAL PROCEDURE}

Radiolabeled methionine, L- $\left[\right.$ methyl- $\left.{ }^{3} \mathrm{H}\right]$ methionine, specific activity $53.7 \mathrm{mCi} / \mathrm{mmol}$, or $\mathrm{L}-\left[{ }^{14} \mathrm{C}(\mathrm{U})\right]$ methionine, specific activity $213 \mathrm{mCi} / \mathrm{mmol}$ was obtained from New England Nuclear, Boston, Massachusetts.

Astrocytes were grown in culture as previously described by us (6). Confluent cultures show a typical astroglial morphology and ubiquitously stain with glial-specific histological stains. Comparably prepared cultures from neonatal rat brains are enriched in the astrocytespecific GFA protein (3). Cultures were used at confluence 12-14 days after seeding, fortyeight hours following the last feeding.

The buffer used for the MET uptake experiments contained $5.3 \mathrm{mM} \mathrm{KCl}, 150 \mathrm{mM} \mathrm{NaCl}$, $1 \mathrm{mM} \mathrm{CaCl}_{2}, 600 \mu \mathrm{M} \mathrm{MgCl}_{2}, 1.6 \mathrm{mM} \mathrm{KH}_{2} \mathrm{PO}_{4}$, and $4.3 \mathrm{mM} \mathrm{Na}_{2} \mathrm{HPO}_{4}, \mathrm{pH}$ 7.2. When the ionic composition of the buffer was varied, $\mathrm{Na}^{+}$was substituted iso-osmotically for $\mathrm{K}^{+}$.

To determine MET uptake, $60 \times 15 \mathrm{~mm}$ dishes of confluent astrocytes $\left(10^{4}\right.$ cells $)$ were washed free of medium with $5-7 \mathrm{ml}$ of $37^{\circ} \mathrm{C} 0.9 \% \mathrm{NaCl}$ solution. The rims of the dishes were blotted, and two $\mathrm{ml}$ of buffer containing the appropriate concentration of $\mathrm{K}^{+}, \mathrm{Na}^{+}$ and radiolabeled MET were added. The plates were returned to the incubator at $37^{\circ} \mathrm{C}$, or for incubations shorter than $5 \mathrm{~min}$, dishes were floated in a $37^{\circ} \mathrm{C}$ waterbath. At the appropriate time, the incubation medium was aspirated, and the dishes were rapidly rinsed in ice 
cold isotonic saline ( $15-18 \mathrm{ml}$ ), and the edges were again blotted. Two $\mathrm{ml}$ of $0.2 \mathrm{M}$ perchloric acid were added, and the dishes were stored at $4^{\circ} \mathrm{C}$ overnight. The perchloric acid soluble fraction was removed, neutralized, and duplicate or triplicate aliquots were counted.

To determine non-specific binding, astrocytes were rapidly washed free of tissue culture medium with ice cold $0.9 \% \mathrm{NaCl}$ and two $\mathrm{ml}$ of ice cold buffer containing the same ionic and MET concentration as the experimental samples were rapidly added, swirled, and poured off (5-10 seconds). The cells were again washed in ice cold isotonic saline, disrupted in perchloric acid, and treated as above. Blank values obtained in this manner were subtracted from experimental samples, and the values presented here are corrected for the non-specific binding of tracer amino acid.

To load astrocytes for MET efflux or homoexchange experiments, cells were incubated 10 or $15 \mathrm{~min}$ in a complete buffer containing $6.9 \mathrm{mM} \mathrm{K}^{+}$and $500 \mathrm{nM}$ radiolabeled MET. To estimate the residual MET at the end of the loading time, cells were washed and disrupted in perchloric acid as in the uptake experiments, and the quantity of acid soluble MET determined.

To determine efflux, loaded cells were briefly washed, and $37^{\circ} \mathrm{C}$ MET-free buffer was added, collected and replaced at intervals for the following $45 \mathrm{~min}$. Duplicate $0.25 \mathrm{ml}$ aliquots were counted. The data are expressed as log medium CPM as a percent of the total CPM taken up by the end of the loading period.

Protein was determined by the procedure of Lowry et al. (9) on dishes taken from the same batch, and on the same day as the experimental samples.

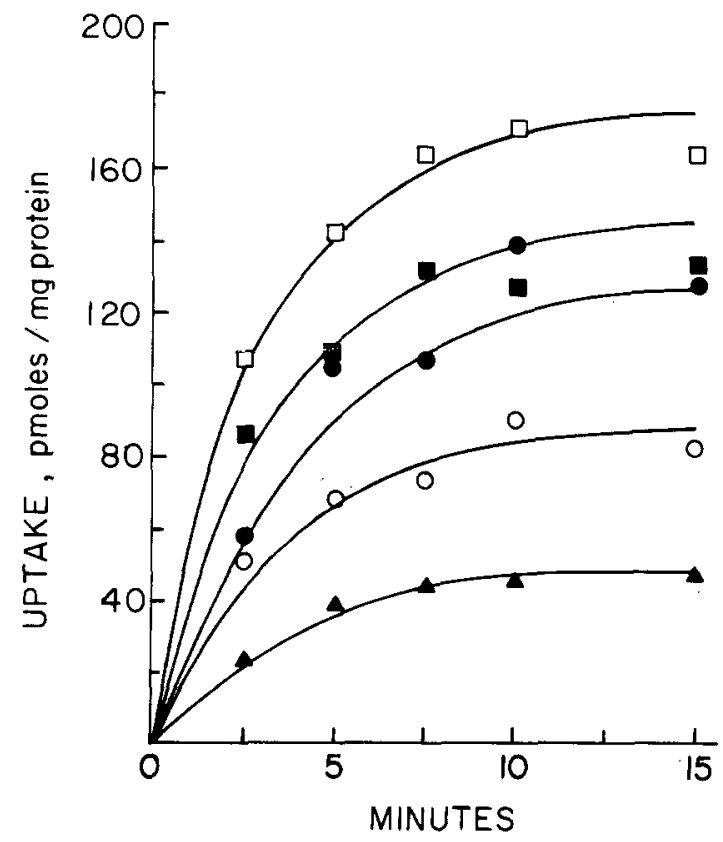

FIG. 1. The time course of methionine uptake is shown for a variety of extracellular methionine concentrations: uptake of 100-500 nM: $100 \mathrm{nM},(A) ; 200 \mathrm{nM}(\bigcirc) ; 300 \mathrm{nM}(\bullet) ; 400$ $\mathrm{nM},(\square)$; and $500 \mathrm{nM},(\square)$. Each point represents duplicate determinations on 3-5 dishes. Standard error was less than $15 \%$ of the mean for all points. 


\section{RESULTS}

To estimate the MET concentrative accumulation, ([intracellular]/[extracellular] or distribution ratio), cell protein was assumed to constitute $10 \%$, and water to constitute $80 \%$ of the wet weight. Uptake indicated per $\mathrm{mg}$ protein is considered to be equivalent to uptake per $8 \mu \mathrm{l}$ of cell water. MET appears in the perchloric acid insoluble fraction in incubations longer than 15 minutes. It is assumed that for short times of incubation ( $<15 \mathrm{~min})$ MET is dispersed in the pool of intracellular water.

The time course of MET uptake is shown in Figure 1. MET uptake is linear for $2.5 \mathrm{~min}$ up to $2.4 \mu \mathrm{M}$ extracellular MET (data not shown). The steady state (i.e. $15 \mathrm{~min}$ ) distribution ratios varied from 37.5 with $100 \mathrm{nM}$ extracellular MET to 47.5 with $500 \mathrm{nM}$ MET.

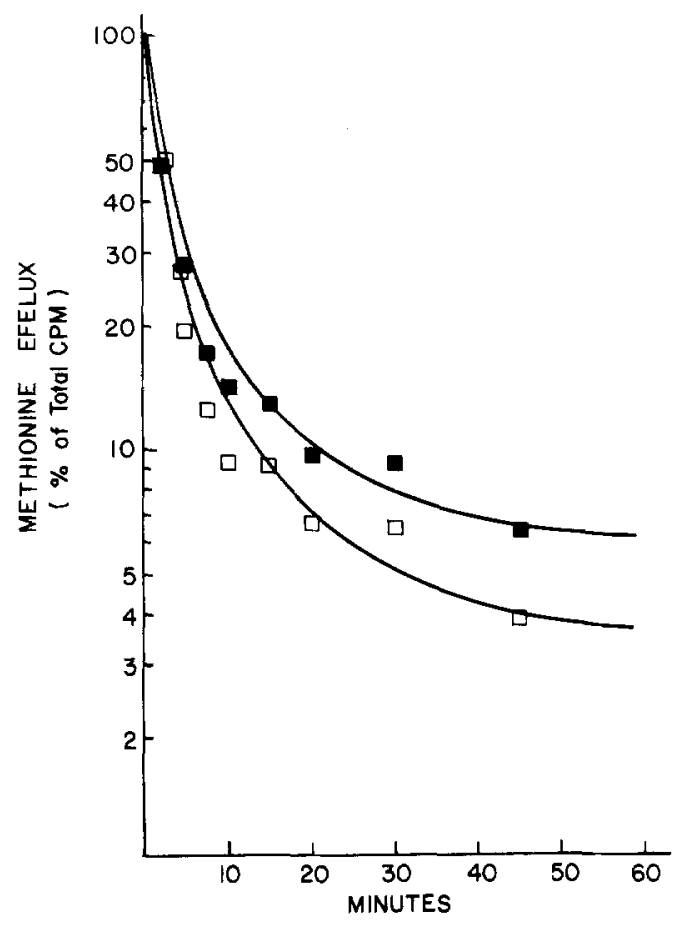

FIG. 2. Dishes of confluent astrocytes were loaded for 15 minutes in $500 \mathrm{nM}$ methionine and $6.9 \mathrm{mM} \mathrm{K}{ }^{+}$buffer. The subsequent washout was followed for 50 minutes in medium containing either 6.9 ( [] ) or $11.9(\mathbb{\square}) \mathrm{mM} \mathrm{K}^{+}$. The results are presented as the efflux of label, as a percent of the total at the end of the loading period. The medium was replaced at the times indicated. Neither the maximum washout nor the initial velocities of efflux are significantly different. Each point represents duplicate determinations on two plates. 


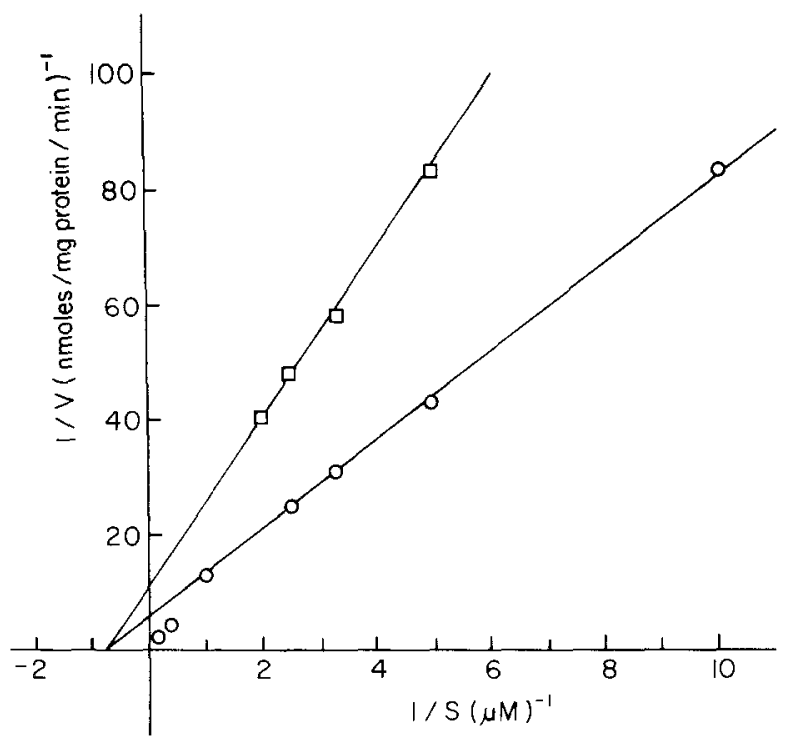

FIG. 3. The Lineweaver-Burk plot of methionine uptake in the presence of $6.9 \mathrm{mM} \mathrm{K}{ }^{+}$ (O) or $11.9 \mathrm{mM} \mathrm{K}^{+}(\square)$ is shown. The $K_{m}$ for methionine uptake is $1.3 \mu \mathrm{M}$ at either $\left[\mathrm{K}^{+}\right.$], and the $V_{\max }$ is $182 \mathrm{pmol} / \mathrm{mg}$ protein/min in the presence of $6.9 \mathrm{mM} \mathrm{K} \mathrm{K}^{+}$and $90 \mathrm{nmol} / \mathrm{mg}$ protein $/ \mathrm{min}$ in the presence of $11.9 \mathrm{mM} \mathrm{K}^{+}$. Each point represents the mean of duplicate determinations on 3-5 dishes. The standard error was less than $15 \%$ of the mean.

If elevations in extracellular $\mathrm{K}^{+}$increased the rate of MET efflux, and the rate of MET influx were unaffected, a specious decrease in MET transport would be observed. We therefore determined the effect of extracellular $\mathrm{K}^{+}$on methionine efflux. Cells were loaded with radiolabeled MET, and the effects of 6.9 or $11.9 \mathrm{mM}$ extracellular $\mathrm{K}^{+}$on efflux into MET-free medium were examined (Figure 2). For times shorter than 2.5 minutes, initial rates of MET efflux did not differ significantly. The total MET efflux was also not significantly different for either $\mathrm{K}^{+}$concentration. We interpret these data to indicate that extracellular $\mathrm{K}^{+}$does not affect the rate or endpoint of MET efflux.

The transport of most L-system amino acids shows a homoexchange component (11). To test whether exchange diffusion was a significant aspect of uptake under the experimental conditions, cells were loaded with radiolabeled MET at $500 \mathrm{nM}$, for 10 minutes. The medium was then replaced with buffer containing $6.9 \mathrm{mM} \mathrm{K}^{+}$and various concentrations of unlabeled MET. Homoexchange was measured as efflux of radiolabeled MET "driven" by the concentration of unlabeled extracellular MET. Table I shows that at the concentrations used in this study (100-500 nM) 
TABLE I

Methionine Homoexchange

\begin{tabular}{cccc} 
& \multicolumn{2}{c}{$[\mathrm{MET}]$} & \\
\cline { 2 - 3 } $\begin{array}{c}\text { [MET] ADDED } \\
(\mu \mathrm{M})\end{array}$ & $\begin{array}{c}\text { Efflux } \\
(\mathrm{pmol} / 2.5 \mathrm{~min} / \mathrm{mg} \text { protein) }\end{array}$ & $\begin{array}{c}\text { \% Total Pool } \\
\text { Exchanged }\end{array}$ \\
\hline None & $268.1 \pm 13.62$ & & \\
0.1 & $239.7 \pm 6.53$ & $-0-$ & $-0-$ \\
1.0 & $277.0 \pm 9.39$ & 8.9 & 5.0 \\
10.0 & $336.3 \pm 7.62$ & 68.2 & 37.9 \\
100.0 & $468.8 \pm 15.83$ & 200.7 & 111.5 \\
500.0 & $476.3 \pm 10.28$ & 208.6 & 115.6 \\
\hline
\end{tabular}

Dishes of confluent astrocytes were treated with $500 \mathrm{nM}$ radiolabeled MET for $10 \mathrm{~min}$ in a buffer containing $6.9 \mathrm{mM} \mathrm{K}^{+}$. At the end of the loading period the total intracellular MET pool was $180 \mathrm{pmol} / \mathrm{mg}$ protein. The medium was changed to buffer containing no MET (control) or various concentrations of unlabeled MET as indicated in column 1. Two and one half min later, the medium was removed, and the quantity of radiolabeled MET in the medium determined (column 2, mean \pm SEM). The radiolabeled MET appearing after medium replacement in the absence of added MET (line 1) represents MET efflux (c. $f$. Figure 2), as well as residual MET adhering non-specifically. MET homoexchange (column 3) was calculated by subtracting the efflux value obtained in the absence of added MET (268.1 pmol $/ 2.5 \mathrm{~min} / \mathrm{mg}$ protein) from the values obtained in the presence of the various MET concentrations. The per cent of the total pool exchanged is calculated by dividing the MET homoexchanged by the total MET pool at the end of the loading period ( $180 \mathrm{pmol} / \mathrm{mg}$ protein).

homoexchange comprised less than $5 \%$ of the total apparent uptake. Thus, for concentrations of MET less than $1 \mu \mathrm{M}$, and at times less than $2.5 \mathrm{~min}$ apparent MET uptake cannot be accounted for by either homoexchange, efflux, or incorporation into protein, and represents true unidirectional flux.

Initial velocities were extrapolated from the timecourse data of Figure 1 , and the calculated fraction of homoexchange was subtracted. A Lineweaver-Burk plot is shown in Figure 3. For MET uptake in the presence of $6.9 \mathrm{mM} \mathrm{K}^{+}$the apparent $V_{\max }$ is $182 \mathrm{pmoles} / \mathrm{mg}$ protein $/ \mathrm{min}$, and the $K_{m}$ is $1.3 \mu \mathrm{M}$. In the presence of $\mathrm{K}^{+}$at $11.9 \mathrm{mM}$, the $K_{m}$ is unchanged, but the $V_{\max }$ is markedly decreased, to $90.9 \mathrm{pmol} / \mathrm{mg}$ protein $/ \mathrm{min}$.

\section{DISCUSSION}

The general features of amino acid transport in other mammalian systems are also seen in brain slice preparations (13). MET uptake has not been widely examined in nervous tissue, and distribution ratios are not known. Distribution ratios vary from 37 to 47 in buffers containing 6.9 
$\mathrm{mM} \mathrm{K}{ }^{+}$. These values are higher than those reported by Belkhode and Scholefield (1) for non-nervous tissue.

The apparent uptake of MET was significantly reduced when the extracellular $\mathrm{K}^{+}$was increased to $11.9 \mathrm{mM}$, and elevations beyond 11.9 $\mathrm{mM}$ did not cause a further reduction in MET uptake (6). MET uptake in the range of $1 \mu \mathrm{M}$ and less does not result from the interaction of potassium levels and mechanisms regulating homoexchange and efflux, but rather appears to affect the velocity of transport directly. The generality of this effect is still an open question, since extracellular $\mathrm{K}^{+}$levels do not effect the uptake of either $\beta$-alanine or $\alpha$-aminoisobutyrate (4). Schousboe et al. (12) have recently demonstrated a $\mathrm{K}^{+}$-induced alteration in the uptake of GABA, perhaps by a mechanism similar to the one observed here.

The upper range of extracellular $\mathrm{K}^{+}$observed in normal, stimulated intact cortex (measured by ion-specific electrodes) appears to be no greater than $12 \mathrm{mM}(2,14)$, and the concentrations of $\mathrm{K}^{+}$which affected MET uptake are within this physiological concentration. We reported $(4,6)$ that elevated $\mathrm{K}^{+}$and norepinephrine reciprocally modulated the uptake of the glucose analog, 2-deoxy-D-glucose, in rat brain astrocytes. This suggests that the production of potassium by rapidly firing neurons may alter important physiological processes of the surrounding glia, such as membrane potential, metabolism and amino acid uptake. Brain L-system amino acids include, among others, tyrosine and tryptophan (13). A potassium-induced decrease in the glial uptake of other L-system amino acids may therefore increase the availability of neurotransmitter precursors. Thus, the role of extracellular $\mathrm{K}^{+}$may represent an important physiological control in the neuronal modulation of astrocytic metabolism in vitro as well as in vivo.

\section{REFERENCES}

1. Belkhode, M., and Scholefield, P. G. 1969. Interactions between amino acids during transport and exchange diffusion in Novikoff and Erhlich ascites tumor cells. Biochim. Biophys. Acta 179:290-301.

2. Benninger, C., Kadis, J., and Prince, D. A. 1980. Extracellular calcium and potassium changes in hippocampal slices. Brain Res. 187:165-182.

3. Bock, E., Moller, M., Nissan, C., and Sensenbrenner, M. 1977. Glial fibrillary acidic protein in primary astroglial cell cultures derived from newborn rat brain. FEBS Lett. 83:201-211.

4. Cummins, C. J. 1977. The effect of extracellular $\mathrm{K}^{+}$on the intermediary metabolism of primary astrocytes in vitro. Dissertation Abstracts.

5. Cummins, C. J., and Glover, R. A. 1978. Propagation and histological characterization of a homotypic population of astrocytes derived from neonatal rat brain. J. Anat. (L) 125:117-125. 
6. Cummins, C. J., Glover, R. A., and Sellinger, O. Z. 1979. Neuronal cues regulate uptake in cultured astrocytes. Brain Res. 170:190-193.

7. Hertz, L. 1966. Neuroglial localization of potassium and sodium effects on respiration in brain. J. Neurochem. 13:1373-1387.

8. Lothman, E. W., LaManna, J., Cordingly, G., Rosenthal, M., and Somjen, G. 1975. Response of electrical potential, potassium levels and oxidative metabolic activity in the cerebral neocortex of cats. Brain Res. 88:15-36.

9. Lowry, O. H., Rosenbrough, N., Farr, A., and Randall, R. 1951. Protein measurement with the Folin phenol reagent. J. Biol. Chem. 193:265-275.

10. MAker, H. S., Clarke, D. D., and LAJThA, A. L. 1976. Intermediary metabolism of carbohydrates and amino acids. Pages 279-307, in Siegel, G. J., Albers, R. W., KatzMan, R., and AgranofF, B. W. (eds.) Basic Neurochemistry. Little, Brown and Co., Boston.

11. Potashner, S., and Johnson, R. 1970. Cations, transport and exchange diffusion of methionine in Ehrlich ascites cells. Biochem. Biophys. Acta 203:445-456.

12. Schousboe, A., Hertz, L., and Svenneby, G. 1977. Uptake and metabolism of GABA in astrocyte cultures from dissociated brain hemispheres. Neurochem. Res. 2:217-229.

13. Sershen, H., and LaJThA, A. 1979. Inhibition pattern by analogs indicates the presence of ten or more transport systems for amino acids in brain cells. J. Neurochem. 32:719-726.

14. Somjen, G., Rosenthal, M., Cordingly, G., LaManna, J, and Lothman, E. 1976. Potassium, neuroglia and oxidative metabolism in central gray matter. Fed. Proc. 35:1266-1271. 